http://dx.doi.org/10.11646/zootaxa.3710.1.4

http://zoobank.org/urn:lsid:zoobank.org:pub:36BEB161-20B5-472C-9815-53C86AD647E1

\title{
Feather mites of the genus Zachvatkinia Dubinin, 1949 (Astigmata: Analgoidea: Avenzoariidae) from Saudi Arabia: A new species and two new records
}

\author{
MOHAMED W. NEGM ${ }^{1,4,5}$, MOHAMED G. E.-D. NASSER ${ }^{2}$, FAHAD J. ALATAWI ${ }^{1}$, \\ AZZAM M. AL AHMAD² \& MOHAMMED SHOBRAK ${ }^{3}$ \\ ${ }^{1}$ Acarology Laboratory, Department of Plant Protection, College of Food \& Agriculture Sciences, King Saud University, Riyadh \\ 11451, P.O. Box 2460, Saudi Arabia \\ ${ }^{2}$ Medical \& Veterinary Entomology Unit, Department of Plant Protection, College of Food \& Agriculture Sciences, King Saud Univer- \\ sity, Riyadh 11451, P.O. Box 2460, Saudi Arabia \\ ${ }^{3}$ Department of Biology, College of Science, Taif University, Taif, P.O. Box 888, Saudi Arabia \\ ${ }^{4}$ Permanent address: Department of Plant Protection, Faculty of Agriculture, Assiut University, Assiut 71526, Egypt. \\ ${ }^{5}$ Corresponding author. E-mail: waleednegm@yahoo.com
}

\begin{abstract}
Feather mites of the family Avenzoariidae (Acari: Astigmata: Analgoidea) are recorded for the first time in Saudi Arabia. A new avenzoariid species, Zachvatkinia (Zachvatkinia) repressae sp. n. (Avenzoariidae: Bonnetellinae), is described from the White-cheeked Tern, Sterna repressa Hartert, 1916 (Charadriiformes: Sternidae). The new species belongs to the sternae group and is closely related to Z. (Z.) chlidoniae Mironov, 1989a. Two more species, Z. (Z.) dromae Mironov, 1992 and Z. (Z.) sternae (Canestrini \& Fanzago, 1876), were collected from the Crab Plover Dromas ardeola Paykull, 1805 (Charadriiformes: Dromadidae) and the Sooty Gull Ichthyaetus hemprichii (Bruch, 1853) (Charadriiformes: Laridae), respectively. Among the 18 described species of Zachvatkinia Dubinin, 1949, including the new species, this is the fifth species recorded from a sternid host. The remaining 13 nominal species are associated with birds of the families Diomedeidae, Dromadidae, Hydrobatidae, Laridae, Pelecanoididae, Procellariidae and Stercorariidae. A checklist of world species of Zachvatkinia with data on their distribution and type hosts is also provided.
\end{abstract}

Key words: Astigmata, feather mites, Avenzoariidae, Bonnetellinae, new species, Zachvatkinia, Saudi Arabia

\section{Introduction}

The feather mite genus Zachvatkinia Dubinin, 1949 (Astigmata: Analgoidea: Avenzoariidae: Bonnetellinae) was originally established by Trouessart (1916) under the name Giebelia Trouessart, 1916. Since the latter name appeared preoccupied, Dubinin (1949) proposed a replaced name Zachvatkinia. This genus currently includes 18 nominal species (Buchholz 1869; Canestrini \& Fanzago 1876; Bonnet 1924; Dubinin 1949; Chirov 1978; Mironov 1989a, b, 1991b, 1992; Mironov \& Stefan 2013) (Table 1). Mironov (1989b) divided the genus into two subgenera, Zachvatkinia and Rhinozachvatkinia, on the basis of the structure of their gnathosoma and form of setae $m G$ of genua I. The most extensive work on this genus has been done by Mironov (1989a, b, 1991a, b, 1992). Representatives of this genus occur on various avian families of the orders Charadriiformes (Dromadidae, Laridae, Stercorariidae and Sternidae) and Procellariiformes (Diomedeidae, Hydrobatidae, Pelecanoididae and Procellariidae) (Table 1).

Including mites, external parasites of wild birds are poorly studied in Saudi Arabia (El-Ahmed et al. 2012). Bafort and Fain (1984) reported endoparasitic hypopi of Phalacrodectes (Peledectes) punctatissimus Cerny, 1969 and Pelecanectes apunctatus Pence \& Courtney, 1973 (Sarcoptiformes: Hypoderoidea: Hypoderidae) from the air sacs of the Great White Pelican, Pelecanus onocrotalus Linnaeus, 1758 (Pelecaniformes: Pelecanidae) in Dammam, Eastern province. The present study is a first step in surveying the ectoparasite fauna associated with marine birds in Saudi Arabia. 
This present work contributes to the knowledge of Asian feather mites by describing a new Zachvatkinia species from the White-cheeked Tern, Sterna repressa Hartert, 1916 (Charadriiformes: Sternidae). We also report for the first time two more species of the genus Zachvatkinia for Saudi Arabia.

TABLE 1. Checklist of Zachvatkinia subgenera and species with distribution and type hosts.

\begin{tabular}{|c|c|c|c|c|}
\hline Mite species & Type host & Host family & Type locality & Reference \\
\hline $\begin{array}{l}\text { Zachvatkinia } \\
\text { (Rhinozachvatkinia) graciosa }\end{array}$ & Pachyptila desolata & Procellariidae & South Georgia Island & Mironov, 1989b \\
\hline Z. (R.) pelecanoidi & Pelecanoides georgicus & Pelecanoididae & South Georgia Island & Mironov, 1989b \\
\hline Z. (R.) zygoloba & $\begin{array}{l}\text { Oceanodroma } \\
\text { leucorhoa }\end{array}$ & Hydrobatidae & South Georgia Island & Mironov, 1989b \\
\hline Z. (Zachvatkinia) caspica & Hydroprogne caspia & Sternidae & Russia: Volga delta & Mironov, 1989a \\
\hline Z. (Z.) chlidoniae & Chlidonias niger & Sternidae & Russia: Volga delta & Mironov, 1989a \\
\hline Z. (Z.) dromae & Dromas ardeola & Dromadidae & Madagascar & Mironov, 1992 \\
\hline Z. (Z.) hydrobatidii & Oceanites oceanicus & Hydrobatidae & USA: Massachusetts & Dubinin, 1949 \\
\hline Z. (Z.) isolata & Stercorarius parasiticus & Stercorariidae & $\begin{array}{l}\text { Russia: Ainovy } \\
\text { Islands }\end{array}$ & Mironov, 1989a \\
\hline Z. (Z.) issykkulica & Sterna albifrons & Sternidae & Kirghizia & Chirov, 1978 \\
\hline Z. (Z.) larica & Larus ridibundus & Laridae & Russia: Volga delta & Mironov, 1989a \\
\hline Z. (Z.) oceanodromae & $\begin{array}{l}\text { Oceanodroma melania } \\
\text { melania }\end{array}$ & Hydrobatidae & $\begin{array}{l}\text { Russia: Komandor } \\
\text { Islands }\end{array}$ & Mironov, 1989a \\
\hline Z. (Z.) ovata & $\begin{array}{l}\text { Calonectris diomedea } \\
\text { borealis }\end{array}$ & Procellariidae & North-East-Atlantic & Mironov, 1989a \\
\hline Z. (Z.) oxyloba & Dromas ardeola & Dromadidae & Madagascar & Mironov, 1992 \\
\hline Zachvatkinia (Z.) puffini & Procellaria cinerea & Procellariidae & Madagascar & Buchholz, 1869 \\
\hline Z. (Z.) stercorarii & Stercorarius pomarinus & Stercorariidae & $\begin{array}{l}\text { Russia: Wrangel } \\
\text { Island }\end{array}$ & Dubinin, 1949 \\
\hline Z. (Z.) sternae & Chlidonias niger & Sternidae & Italy & $\begin{array}{l}\text { Canestrini \& } \\
\text { Fanzago, } 1876\end{array}$ \\
\hline Z. (Z.) trouessarti & $\begin{array}{l}\text { Thalassarche } \\
\text { chlororhynchos }\end{array}$ & Diomedeidae & Antarctica & Bonnet, 1924 \\
\hline Z. (Z.) repressae & Sterna repressa & Sternidae & Saudi Arabia & Present study \\
\hline
\end{tabular}

\section{Material and methods}

During a field survey of the chewing lice fauna of birds of Saudi Arabia, one of us (M.G. Nasser) had the opportunity to examine three species of marine birds for mites. Breeding sites of these birds were located at three different islands: Farasan Archipelago $\left(16^{\circ} 50^{\prime} 4^{\prime \prime} \mathrm{N}, 42^{\circ} 1^{\prime} 38^{\prime \prime} \mathrm{E}\right)$ for the crab plover; Umm Al-Malik Island, Red Sea $\left(25^{\circ} 13^{\prime} 48^{\prime \prime} \mathrm{N}, 37^{\circ} 8^{\prime} 37^{\prime \prime} \mathrm{E}\right)$ for the sooty gull and Jana Island, Arabian Gulf $\left(27^{\circ} 22^{\prime} 10^{\prime \prime} \mathrm{N}, 49^{\circ} 53^{\prime} 53^{\prime \prime} \mathrm{E}\right)$ for whitecheeked tern. The host species were identified using two different field guides to birds of the Middle East (Cottridge 2006; Porter \& Aspinall 2010).

Birds were caught using two methods: a standard mist-net (mesh, $1.8 \mathrm{~cm} \times 0.12 \mathrm{~mm}$; size, $2 \mathrm{~m} \times 15 \mathrm{~m}$ ) for catching sooty gulls and crab plovers while ground traps were used to catch white-cheecked terns. Visual inspection was used to determine the presence of mites. Feather mites were visible along the shaft and/or between the barbs of the infested primary feathers. Mites were collected either by using a fine forceps or by cutting a part of the infested feather(s). The collected mites were preserved in 70\% ethanol, and then brought to the Acarology Laboratory at King Saud University for identification. Mite specimens were mounted in Hoyer's medium and examined under a phase-contrast microscope (DM2500, Leica ${ }^{\circledR}$, Germany). Drawings were made using a drawing tube (Olympus ${ }^{\circledR}$, Japan) attached to the microscope. Images of mites were taken with an Auto-Montage software 
system (Syncroscopy ${ }^{\circledR}$, Cambridge, UK) with the aid of a camera (Q-Imaging, MicroPublisher 0.5 RTV) controlled by AcQuis image capture software. All measurements are presented in microns $(\mu \mathrm{m})$.

The holotype and most of the paratypes are deposited at King Saud Museum of Arthropods, Riyadh, Saudi Arabia (KSMA) while a paratype male and female will be deposited at the Acarology Laboratory, Museum of Biological Diversity, The Ohio State University, 1315 Kinnear Road, Columbus, Ohio 43212, USA.

\section{Family Avenzoariidae Oudemans, 1905}

\section{Subfamily Bonnetellinae Atyeo \& Gaud, 1981}

\section{Genus Zachvatkinia Dubinin, 1949}

\section{Zachvatkinia (Zachvatkinia) repressae Negm \& Alatawi sp. n.}

(Figs. 1-9)

Type material. Male holotype (KSMA), 8 male and 18 female paratypes ex Sterna repressa Hartert, 1916 (Charadriiformes: Sternidae), Jana Island, Arabian Gulf, Saudi Arabia, 27²2'10"N, 49 $53^{\prime} 53$ "E, 11 July 2012, leg. M.G. Nasser. Holotype, most male and female paratypes-KSMA; a paratype female and male-The Acarology Laboratory, Museum of Biological Diversity, The Ohio State University.

Description. Male (Figs. 1-5) (holotype, range for 4 paratypes in parentheses): gnathosoma length 100 (90105), maximum width 80 (80-85). Idiosoma length 710 (650-720) from anterior end of propodosomal shield to level of bases of setae $h 3$ posteriorly, greatest width 340 (322-348) (Fig. 1). Propodosomal shield: subtriangular, posterolateral angles rounded, posterior margin straight or slightly convex and with a pair of small transversely directed extensions, surface of shield without ornamentation, length along midline 180 (166-180), maximum width 210 (200-228), lengths of scapular setae si 26 (24-26) and se 125 (122-126), distance between setae se-se 180 (173-180) (Fig. 3). Humeral shields well developed, setae $c 235$ (32-36) situated on their anterior ends, lanceolate setae $c 345$ (44-46) long and macrosetae $c p 125$ (122-128) long. Hysteronotal shield: anterior margin straight or slightly concave, anterior angles acute, length from anterior margin to the bases of setae $h 3530$ (515-542), width at anterior margin 300 (288-305). Openings of opisthosomal glands situated anterolateral to setae $e 1$. Terminal cleft narrow, subtriangular, anterior end extending beyond level of setae $e 2$, length of cleft from anterior end to bases of setae $h 3250$ (248-253). Setae ps 160 (57-62) long, situated on lateral margins of supranal concavity, their tips almost extending to bases of setae $h 3$. Macrosetae $h 2$ and $h 3$ with noticeably thickened basal part and with long filiform distal part. Distances between hysteronotal setae: $c 2: d 2165$ (161-172), d2:e2 135 (134-143), e2:f2 132 (132-145),f2:h2 33 (25-33), cl:dl 82 (80-86), d1:el 112 (100-114), el:h1 188 (178-190), h1:h3 120 (116-122), ps2:ps1 45 (45-50).

Epimerites I fused into a Y, sternum without lateral extensions (Fig. 2). Setae 1a 40 (38-41) long, situated on coxal fields I close to epimerites II. Coxal field II open. Epimerites III and IIIa fused, coxal field III closed, setae $3 b$ 50 (45-52) long. Setae $3 a 37$ (35-38) long, situated approximately at same level with setae 3b. Setae 4a37 (37-42) long, situated at same level with genital papillae. Distances between ventral setae: 1a:1a 105 (102-110), 3b:3b 205 (202-212), 4a:4a 97 (95-99), 3a:3a 45 (44-50), g:g 37 (36-42), ps3:ps3 48 (48-50). Distance from genital arch apex to level of setae ps 1230 (212-241). Genital arch shaped as inverted bowl, free ends of its branches directed outward (Fig. 4). Length of genital arch 37 (35-38), width 50 (47-54). Genital shields represented by small and narrow longitudinal strips widely separated from each other, setae $g$ situated on posterior ends of genital shields. Adanal shields fused and form acute median extensions with two small lateral ledges. One pair of additional adanal sclerites shaped as inverted cups present, closely adjacent or poorly connected to adanal apodemes. Bases of setae $g$ and $p s 3$ in subrectangular arrangement. Anal suckers rounded, 35 (32-37) in diameter. Legs III extend beyond lobar apices by full tarsus. Tarsus III with seta $s$ thick, spine-like and tridentate apically (Fig. 5A). Tarsus IV with two dorsobasal spines and with one apical spine-like extension at base of modified seta $e$ (Fig. 5B).

Female (Figs. 6-9) (range for 5 paratypes): gnathosoma length 80-90, width 70-80. Idiosoma: length 440-466 from anterior end of propodosomal shield to level of bases of setae $h 3$, maximum width 280-310 (Fig. 6). Propodosomal shield: subtriangular in shape as in males, posterior margin conspicuously convex, without extensions, lateral angles with small notches posterior to bases of setae se, length along midline 122-130, width at 


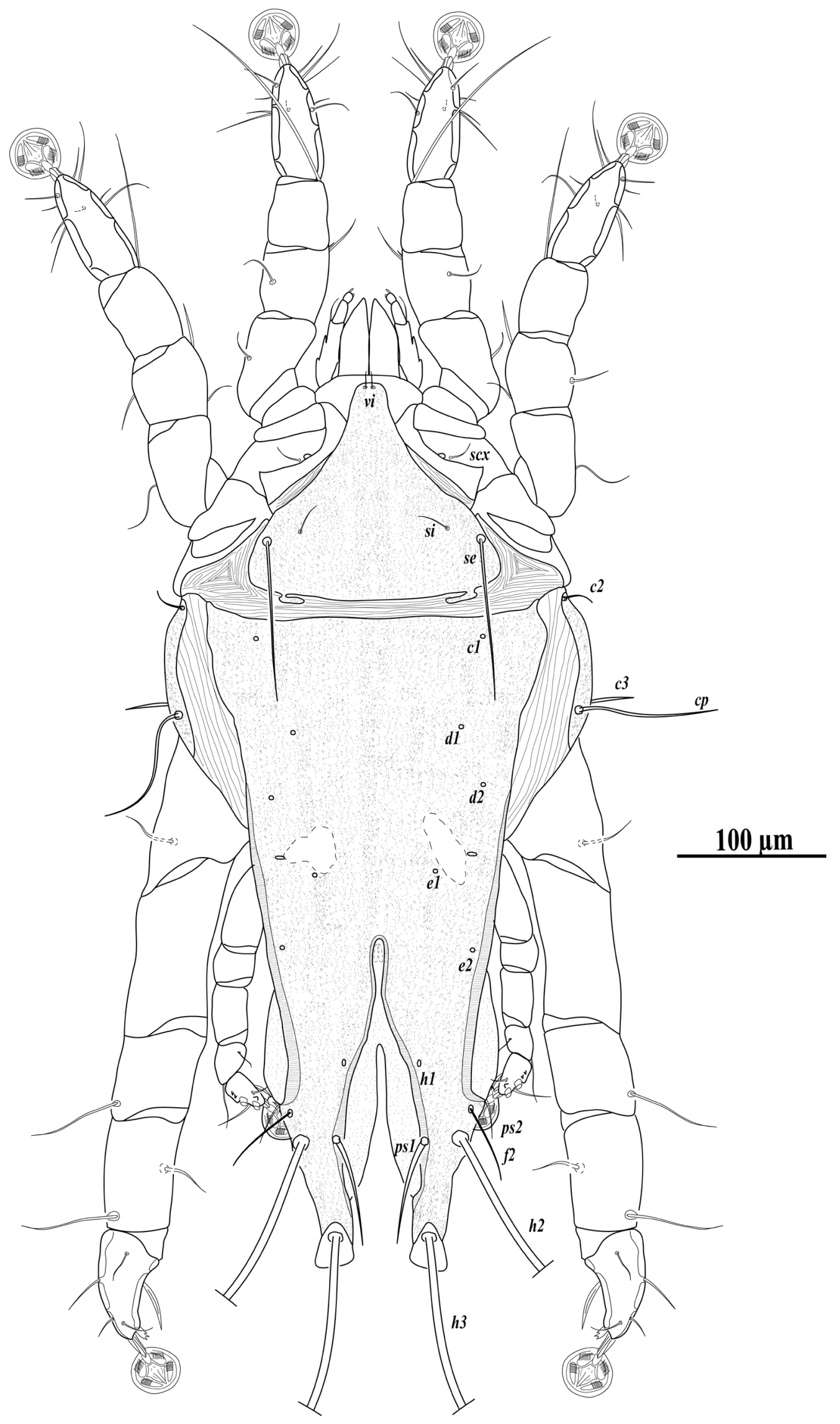

FIGURE 1. Zachvatkinia repressae sp. n., male—dorsum. 


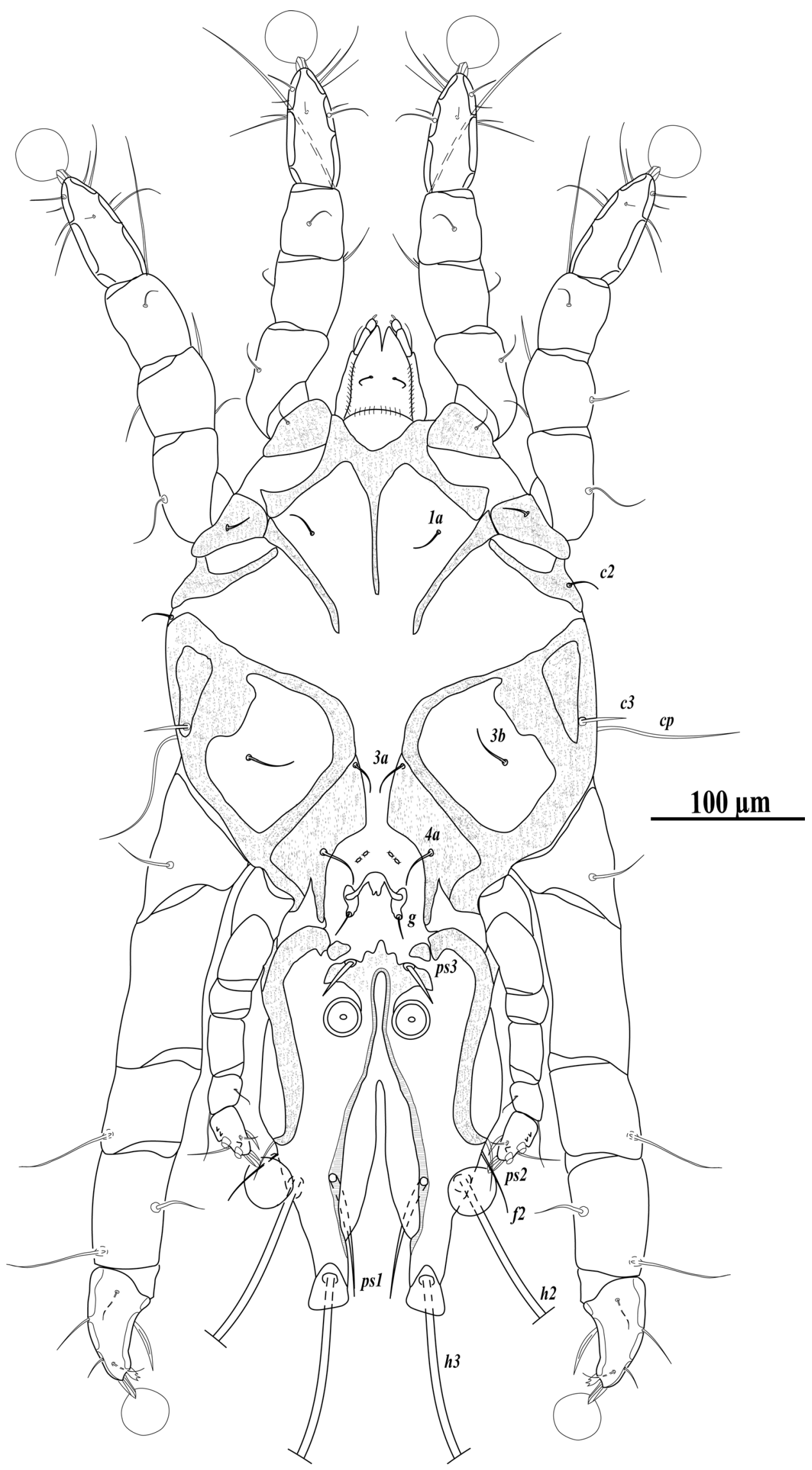

FIGURE 2. Zachvatkinia repressae sp. n., male_-venter. 


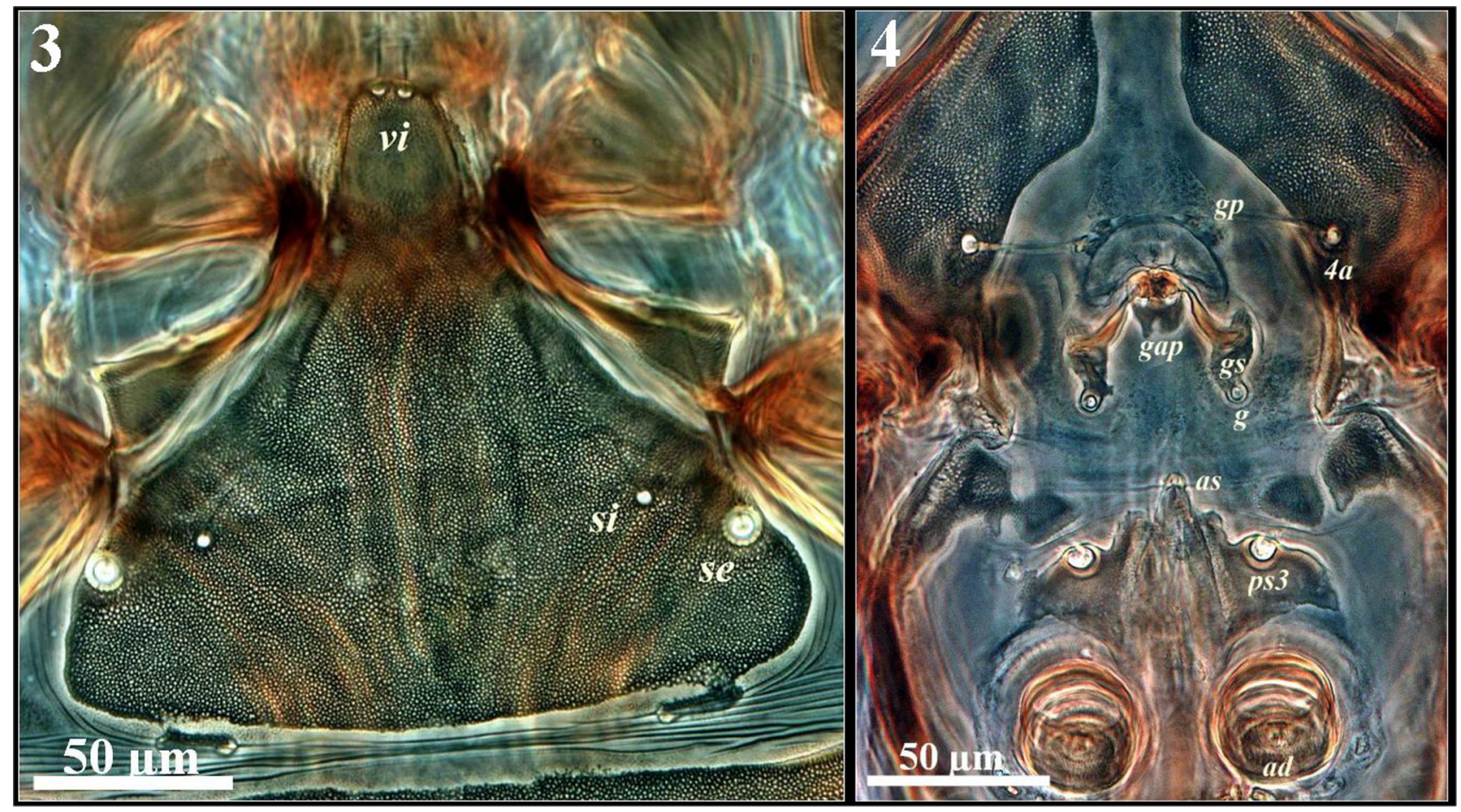

FIGURES 3-4. Zachvatkinia repressae sp. n., male—3, propodosomal shield. 4, genital area. Abbreviations: gp-genital papillae, gap — genital apparatus, gs_ - genital shield, as—adanal shield, ad—anal disk.

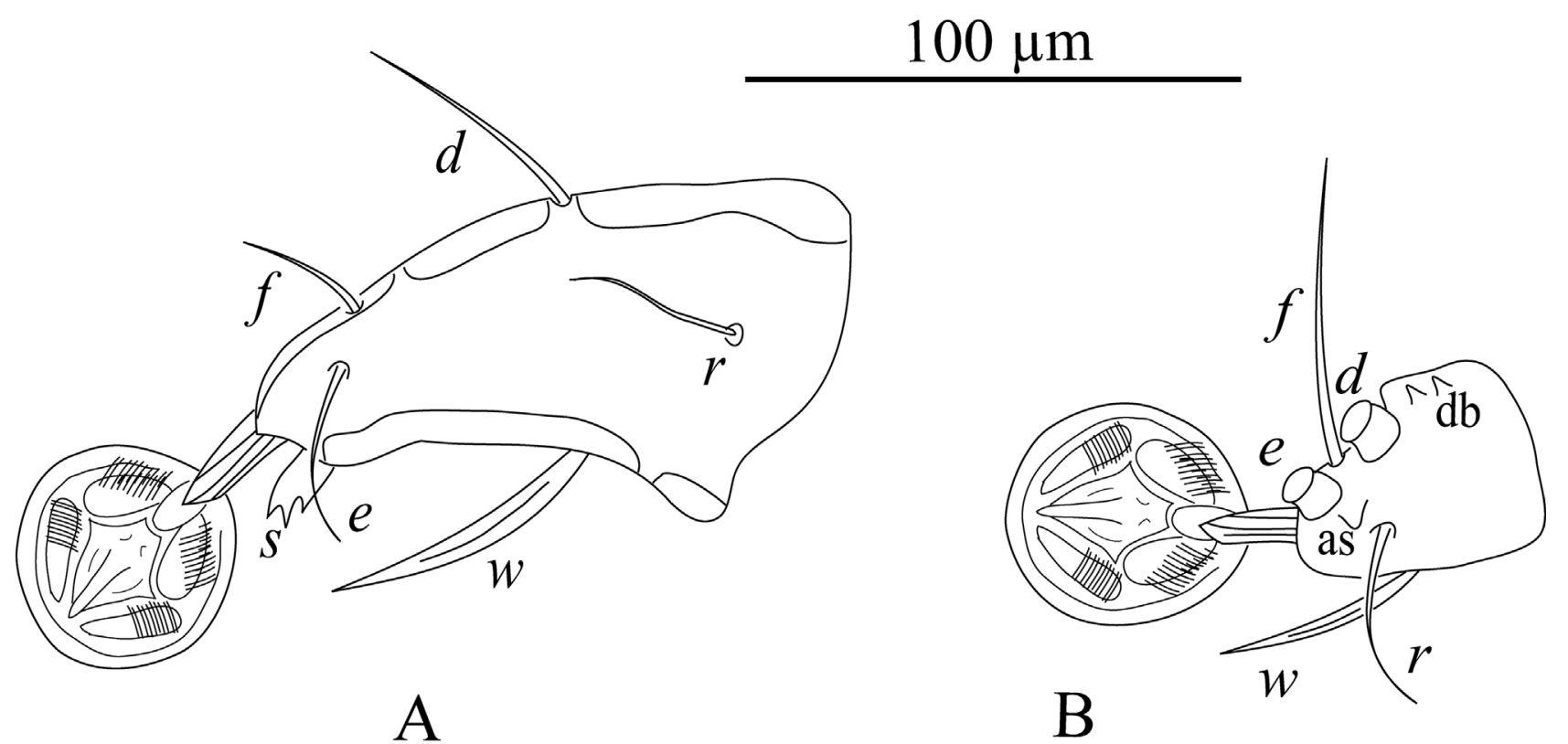

FIGURE 5. Zachvatkinia repressae sp. n., male, A - tarsus III, B - tarsus IV. Abbreviations: as - apical spine-like extension, $\mathrm{db}$ - dorsobasal spine-like extensions.

the level of scapular setae se 144-150, distance between scapular setae si-si 92-100 (Fig. 8). One pair of small transverse sclerites situated between propodosomal shield and transverse row of setae $c 1, c 2$. Humeral shields narrow, not developed dorsally and not extending beyond anterior ends of hysteronotal shields. Setae $c 2$ situated off humeral shields. Humeral setae $c p$ filiform, 80-88 long, subhumeral setae $c 3$ spiculiform, 33-37 long. Hysteronotal shields: one pair of large longitudinal shields along lateral body margins, separated by wide longitudinally striated area. Setae $d l$ situated on median striated integument of hysterosoma, close to inner margins of hysteronotal shields. Pygidial shield present, length 21-25, width 70-76. Distances between hysteronotal setae: $c 2: d 2$ 128-135, d2:e2 110-116, c1:d1 73-77, d1:e1 115-122. 


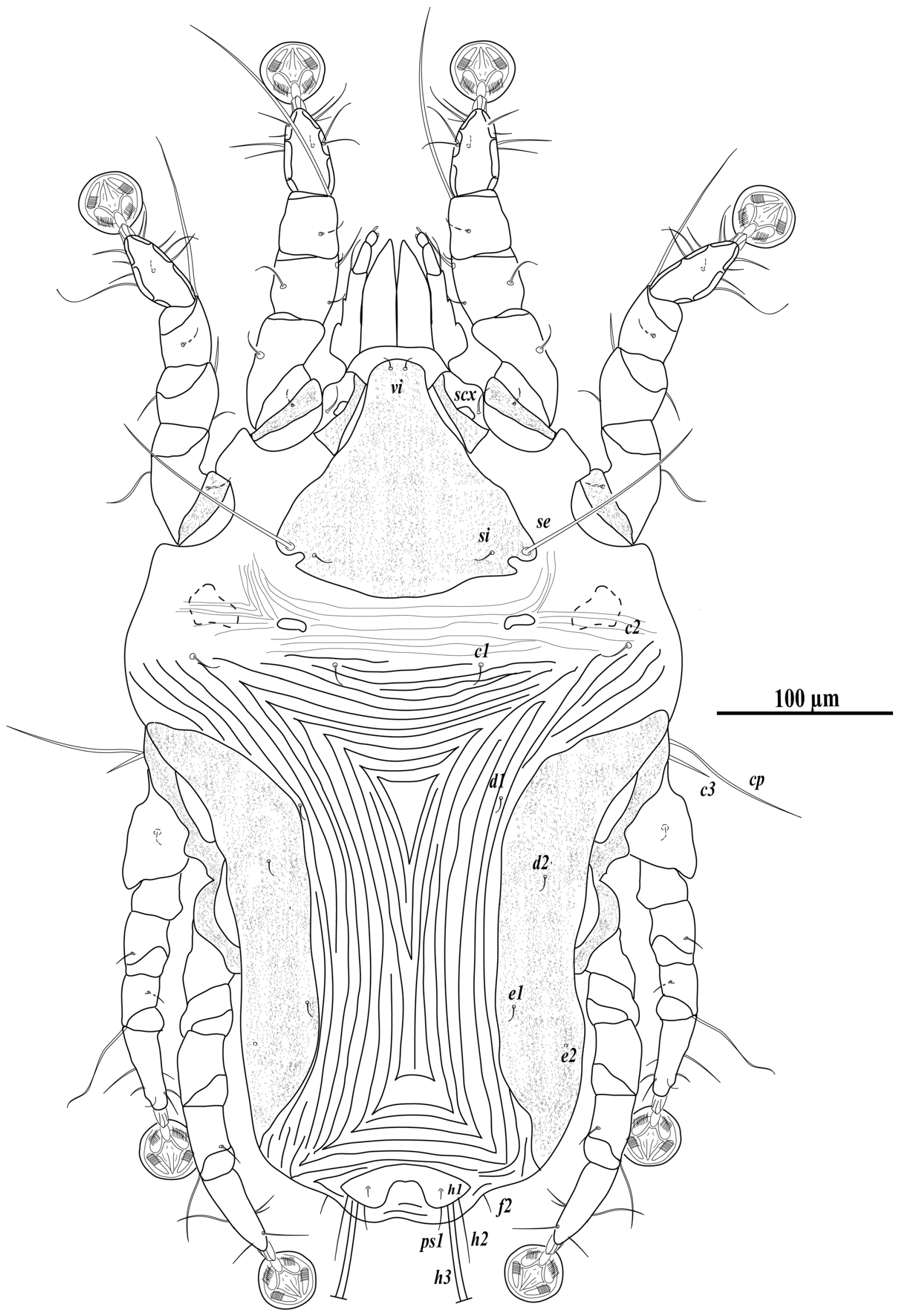

FIGURE 6. Zachvatkinia repressae sp. n., female-dorsum. 


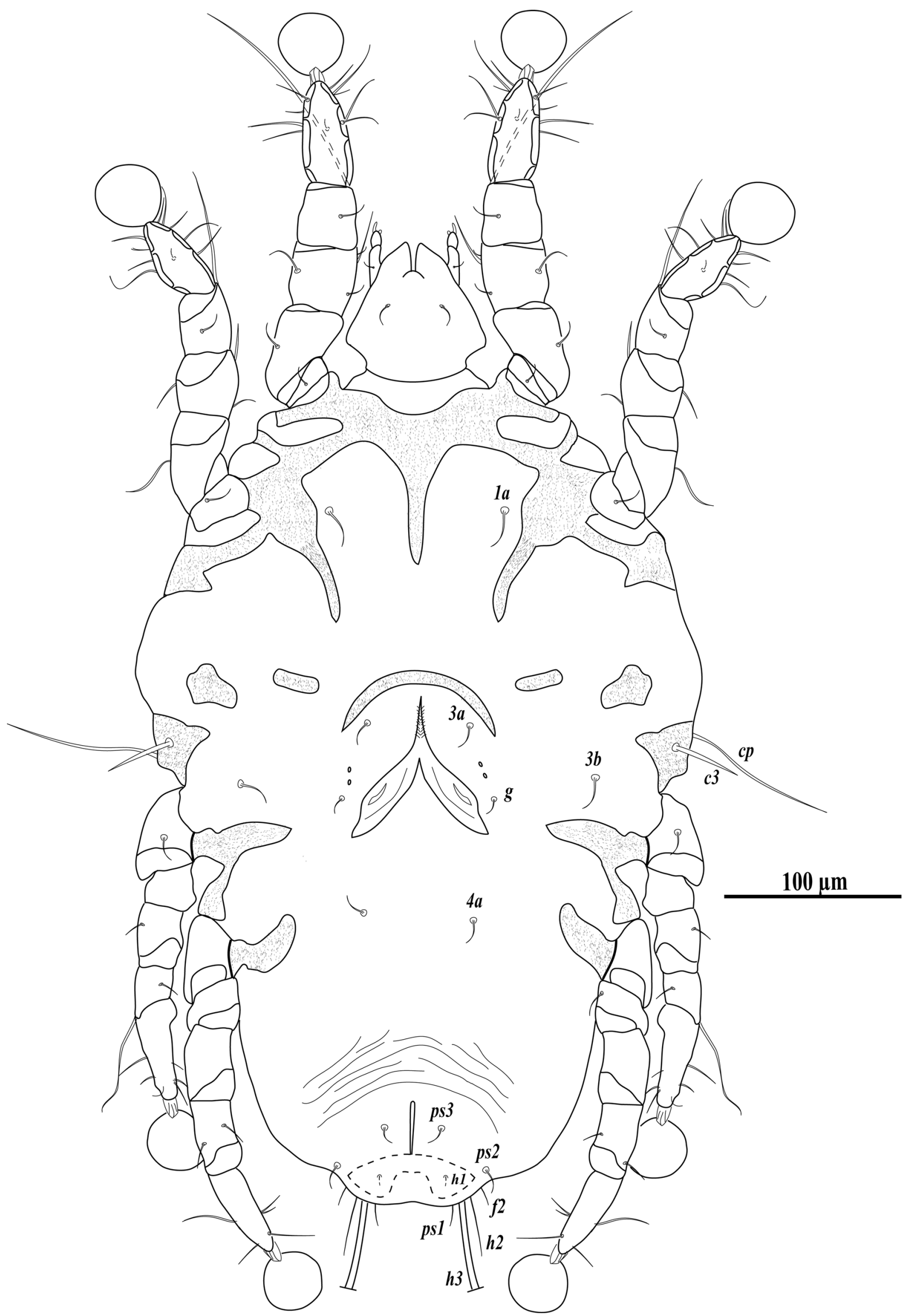

FIGURE 7. Zachvatkinia repressae sp. n., female-venter. 


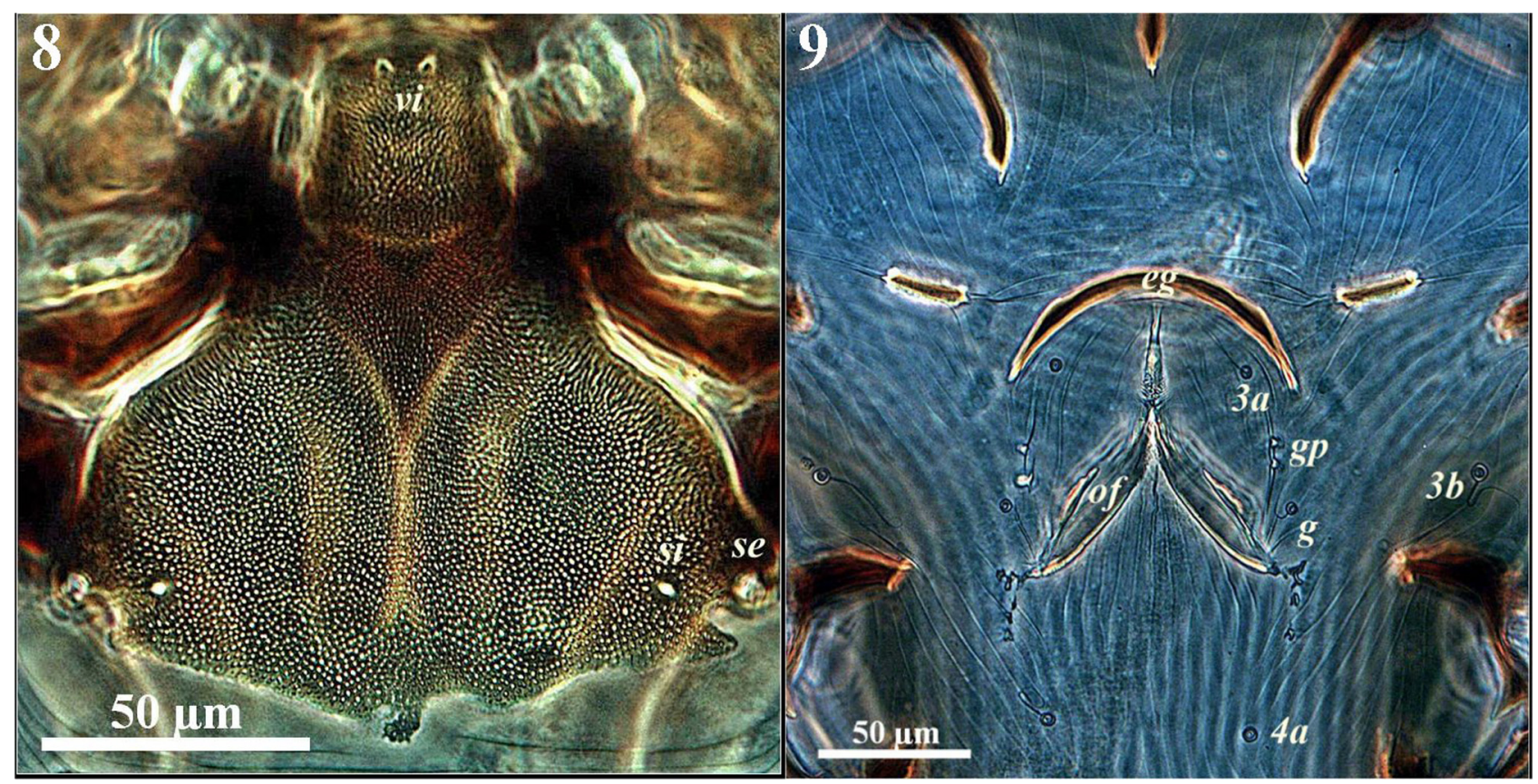

FIGURES 8-9. Zachvatkinia repressae sp. n., female—8, propodosomal shield. 9, genital area. Abbreviations: eg—epigynum, gp_-genital papillae, of-oviporus fold.

Epimerites I fused into a Y (Fig. 7). Length of setae 1a 16-18. Epimerites II free, with pointed tips. Remnants of epimerites IIa not fused with humeral shields. Transverse sclerites situated much anterior to the level of epimerites III, not fused to epigynum. Epimerites III and IVa short. Length of setae 3b 25-30. Setae 3a 14-17 situated anteriorly to level of setae $3 b$, while setae $g$ slightly posterior to them. Distances between ventral setae: la:1a 92-105, 3b:3b 180-205, 3a:3a 51-55, g:g 72-85, 4a:4a 48-56. Epigynum semicircular, bow-shaped, length 35-37, width 75-90, its tips extending slightly beyond level of setae $3 a$ but not reaching level of genital papillae (Fig. 8). Oviporus folds moderate in size and extend to level of epimerites IIIa tips. Tarsi, tibiae, genua and femora of legs I- IV longer than wide. Legs IV extend beyond posterior margin of opisthosoma by distal half of tarsus. Tarsus IV twice as long as corresponding tibia.

Differential diagnosis. The new species $Z$. repressae sp. n. can be differentiated from the morphologically most similar species, Zachvatkinia chlidoniae Mironov, 1989, by the following characters: In males of Z. repressae sp. n., the branches of the genital arch are slightly curved, so that their free ends are directed outward while the anterior end of the arch forms an acute angle, the anterior end of the adanal shield forms an acute angle (Fig. 4), and the posterior margin of propodosomal shield has a pair of small transversely directed extensions (Fig. 3). In males of $Z$. chlidoniae, the branches of the genital arch are strongly S-shaped, so that their free ends are bent forward, the front end of the adanal shield forms an obtuse angle, the posterior margin of propodosomal shield is slightly convex and has no extensions. In females of $Z$. repressae sp. n. the epigynum is 75-90 in width, while in $Z$. chlidoniae it is shorter (64-72) (Mironov, 1989a).

Etymology. The new species epithet repressae derives from the specific name of the type host.

Remarks. In Saudi Arabia, Sterna repressa occurs during the breeding season in summer in many islands of the Arabian Gulf and Red Sea, where it nests. Sterna repressa is distributed through Bahrain, Djibouti, Egypt, Eritrea, India, Iran, Iraq, Israel, Jordan, Kenya, Kuwait, Maldives, Oman, Pakistan, Qatar, Saudi Arabia, Seychelles, Somalia, South Africa, Sudan, Tanzania, United Arab Emirates and Yemen (Porter \& Aspinall 2010).

In his review of the genus Zachvatkinia, Mironov (1989a) largely revised material previously investigated from host species in the Procellariiformes and Charadriiformes in the USSR, resulting in 12 species, of which six were new. Procellariiformes are assumed to be primary hosts for feather mites of the genus Zachvatkinia. The study of host-parasite associations revealed some features of co-evolution both with procellariiform and charadriiform hosts (Mironov, 1991a). 
Zachvatkinia (Zachvatkinia) dromae Mironov, 1992: 497.

Specimens examined. Many males, females and nymphs, from the crab plover, Dromas ardeola Paykull, 1805 (Charadriiformes: Dromadidae), Farasan Archipelago, Jazan province, Saudi Arabia, 16 $50^{\prime} 44^{\prime \prime N}, 42^{\circ} 1{ }^{\prime} 38^{\prime \prime} \mathrm{E}, 17$ July 2012, leg. M.G. Nasser.

Remarks. In Saudi Arabia, the crab plover breeds during summer in some Red Sea islands including Farasan Archipelago and Umm Al-Qamarie Island and are usually never seen in the mainland. It is distributed through the East African coast, Red Sea, Arabian Gulf and Southern coast of Iran, India, Pakistan and Sri Lanka (Baker 1929; Porter \& Aspinall 2010).

The type specimens of $Z$. dromae were collected from $D$. ardeola captured on Providence Island, Madagascar (Mironov 1992: 499). The Saudi specimens are very similar to the description done by Mironov, 1992 who illustrated the propodosomal shield of female without notches at the posterolateral angles; however, some of the Saudi specimens have small notches posterior to scapular setae se. This is the first record of this species in Saudi Arabia. Up to now, Z. dromae is known from just two countries, Madagascar (Mironov 1992) and Saudi Arabia (present study).

\section{Zachvatkinia (Zachvatkinia) sternae (Canestrini \& Fanzago, 1876)}

Dermaleichus sternae Canestrini \& Fanzago, 1876: 109.

Specimen examined. One male ex sooty gull, Ichthyaetus hemprichii (Bruch, 1853) (Charadriiformes: Laridae),

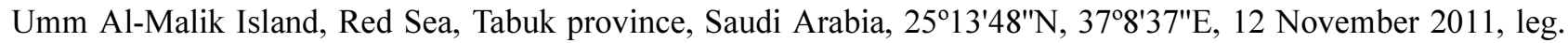
M. Shobrak.

Remarks. In Saudi Arabia, the sooty gull is considered as a coastal gull found throughout the year in the Red Sea and Arabian Gulf, especially around fishing ports. It is distributed through Bahrain, Djibouti, Egypt, Eritrea, India, Iran, Israel, Jordan, Kenya, Lebanon, Maldives, Mozambique, Oman, Pakistan, Qatar, Saudi Arabia, Somalia, Sri Lanka, Sudan, Tanzania, United Arab Emirates and Yemen (Pons et al. 2005; Cottridge 2006; Porter \& Aspinall 2010).

The type specimens of $Z$. sternae were collected from Chlidonias niger (Linnaeus, 1978) in Italy (Canestrini \& Fanzago 1876) and further it was recorded by these authors also from Sterna hirundo Linnaeus, 1758 (Canestrini \& Fanzago 1877). We consider the collection of Z. sternae from I. hemprichii to represent a new host record for this species although we collected only one specimen of it. The Saudi male specimen is very similar to the redescription done by Mironov (1989a: 97) who depicted the ventral setae $c x_{3}(=3 b)$ and $c_{l}(=3 a)$ at one level. However, $3 b$ are distinctly posterior to the level of $3 a$ in the Saudi specimen. We consider this difference to represent intraspecific variation. This is the first record of this species in Saudi Arabia. Z. sternae occurs in Italy (Canestrini \& Fanzago 1876, 1877), Russia (Mironov, 1989a) and Saudi Arabia (present study).

\section{Acknowledgements}

This work was supported by Deanship of Scientific Research and the Research Center of College of Food and Agriculture Sciences at King Saud University. Also, the Deanship of Academic Research in Taif University funded the field trips to North Red Sea Islands and Farasan Archipelago (Grant no. 1-433-2125). We appreciate the help of the Saudi Wildlife Authority in giving permissions to examine wild birds in many protected areas. We would like to thank HH Prince Bander Bin Saud Bin Mohammad, the president of Saudi Wildlife Authority for his sponsorship of this study. Special thanks to Sergey V. Mironov (Zoological Institute, Russian Academy of Sciences, Saint Petersburg, Russia) for confirmation of the new species and for his valuable suggestions while revising the draft version of the manuscript. The authors also thank Dr. Ahmed Mansy, Anas Sampas (Saudi Wildlife Authority) and Mohamed Almalki (PhD student, Bath University, UK) for their help during field work. We greatly appreciate the 
encouragement of our colleagues in Medical and Veterinary Entomology Unit and Acarology Laboratory at King Saud University.

\section{References}

Atyeo, W. \& Gaud, J. (1981) Subfamilies of the Avenzoariidae (Acarina: Analgoidea). Journal of Medical Entomology, 18 (4), $341-344$.

Bafort, J.M. \& Fain, A. (1984) Acarina of Saudi Arabia, hypopi of Hypoderidae (Acarina: Sarcoptiformes) parasites of the white pelican in the Arabian Gulf, Saudi Arabia. Fauna of Saudi Arabia, 6, 162-164.

Baker, E.C. (1929) The game birds of the Indian empire. Part 8. The waders and other semi-sporting birds. Journal of the Bombay Natural History Society, 33 (2), 223-228.

Bonnet, A. (1924) Révision des genres Megninia, Mesalges et genres voisins de la sous-famille des Sarcoptides plumicoles. Bulletin de la Societe zoologique de France, 49, 190-217.

Buchholz, R. (1869) Bemerkungen über die Arten der Gattung Dermaleichus Koch. Verhanll. Kaiser, Leopold. Carolin. Acta Akademie Naturforsch. Dresden, 33, 1-36, 56 S.

Canestrini, G. \& Fanzago, F. (1876) Nuovi Acari Italiani (prima serie). Atti della Societa Veneto-Trentina de Scienze Naturali, $5,99-111$.

Canestrini, G. \& Fanzago, F. (1877) Intorno agli Acari Italiana. Atti Istituto veneto di scienze, lettere ed arti, Ser. 5, 4, 1-140.

Chirov, P.A. (1978) Feather mites (Analgoidea) of Charadriidae, Laridae and Sternidae families of birds from Kirgizia. Izvestiya Akademii Nauk Kirgizskoi SSR., 4, 87-90.

Cottridge, D. (2006) A Photographic Guide to Birds of the Middle East. New Holland Publishers, UK, 63 pp.

Dubinin, V.B. (1949) Feather mites of the Procellariiformes and their particulars. Parazitologicheskiy sbornik, 11, 201-228. [in Russian]

El-Ahmed, A., Nasser, M.G.E.-D., Shobrak, M. \& Dik, B. (2012) First records of the chewing lice (Phthiraptera) associated with European bee eater (Merops apiaster) in Saudi Arabia. Journal of the Egyptian Society of Parasitology, 42 (3), 525533.

Mironov, S.V. (1989a) A brief review of the feather mites of the genus Zachvatkinia in the USSR (Analgoidea, Avenzoariidae). Parazitologiya, 36, 91-115. [in Russian]

Mironov, S.V. (1989b) A new subgenus and three new species of the feather mite genus Zachvatkinia from Procellariiformes. Parazitologiya, 23 (4), 309-319. [in Russian]

Mironov, S.V. (1991a) Coevolutionary relations of feather mites of the family Avenzoariidae (Acariformes: Analgoidea) with birds. Parazitologiya, 25 (6), 473-493. [in Russian]

Mironov, S.V. (1991b) Two new feather mite species of superfamily Analgoidea from Antarctic birds. Informatsionnyi Byulleten Sovetskoi Antarkticheskoi Ekspeditsii. Saint Petersburg, Gidrometeoizdat, 116, 69-75. [in Russian]

Mironov, S.V. (1992) Two new species of feather mites of the genus Zachvatkinia (Analgoidea: Avenzoariidae) from Crab Plover. Parazitologiya, 26 (6), 497-505. [in Russian]

Mironov, S.V. \& Stefan, L.M. (2013) Redescription of the feather mite species, Zachvatkinia puffini (Buchholz, 1869) (Acariformes: Avenzoariidae), from its type host, the Grey Petrel Procellaria cinerea (Procellariiformes: Procellariidae). Acarina, 21 (1), 27-37.

Oudemans, A.C. (1905) Acarologische aanteekeningen XV. Entomologische Berichten, 1, 207-210.

Pons, J.-M., Hassanin, A., \& Crochet, P.-A. (2005) Phylogenetic relationships within the Laridae (Charadriiformes: Aves) inferred from mitochondrial markers. Molecular Phylogenetics and Evolution, 37 (3), 686-699. http://dx.doi.org/10.1016/j.ympev.2005.05.011

Porter, R. \& Aspinall, S. (2010) Birds of the Middle East, 2nd Edition. Princeton University Press, USA, 384 pp.

Trouessart, E.L. (1916) 1915. Révision des genres de la sous-famille des Analgesinae, ou Sarcoptides plumicoles. Bulletin de la Société zoologique de France, 40, 207-223. 